\title{
ENTREVISTA CON JOSEFINA MOLINA. Escritora, directora y Presidenta de Honor de CIMA (Asociación de Mujeres Cineastas y de Medios Audiovisuales)
}

\author{
Natalia Contreras de La Llave \\ Universidad de Alicante
}

"Todavía se valoran menos las películas de mujeres"

Abrir camino siempre es difícil, pero trabajar en cine y televisión en pleno franquismo significaba luchar, en el plano artístico, contra un sistema que usaba el cine como vehículo imprescindible de transmisión ideológica, que trataba a las mujeres como menores de edad, al que le aterrorizaba lo diferente y que estaba dispuesto a barrer cualquier atisbo de crítica. Todo ello convierte a aquellas directoras en un referente artístico e ideológico de nuestro país que es necesario sacar a la luz, valorar en su justa medida e incluso enseñar en las escuelas. Josefina Molina (1936, Córdoba) fue la primera mujer en graduarse en la Escuela de Cine de Madrid (tras haberse licenciado a su vez en Ciencias

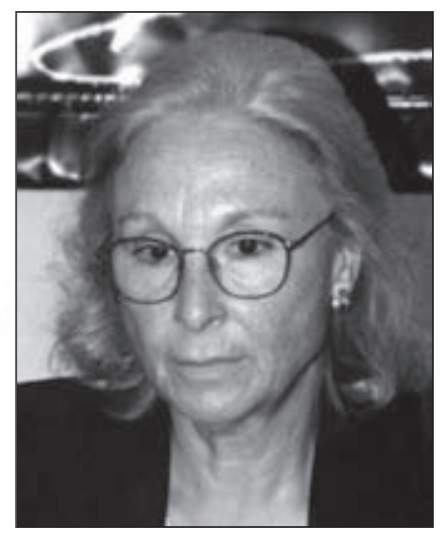
Políticas por la UCM). Junto con Pilar Miró y Cecilia Bartolomé, se convirtió en una pionera en el mundo del cine en España cuyo testimonio es, hoy en día, fundamental y clarificador tanto sobre nuestro pasado como sobre nuestro presente.

"Hoy lo subversivo es el sentido común", afirma Josefina Molina en esta entrevista, donde reivindica otra mirada y, consecuentemente, otro mundo donde la Humanidad vea "con dos ojos en vez de uno", según sus palabras.

Desde Vera, un cuento cruel (1974) hasta su última novela, Los papeles de Bécquer (2000), la obra de esta directora ha estado marcada, además, por la literatura y el teatro. En su haber, la visión compleja de la figura de Teresa de Jesús (en partes de cuyo guión colaboró la escritora Carmen Martín Gaite) y la cinta histórica Esquilache (de 1988, basada en la obra 
teatral de de Buero Vallejo Un soñador para un pueblo). Su película Función de noche (1981) nos deja, según K. Vernon", una "contra-herencia cultural" y una interpelación al franquismo desde un punto de vista de género. Una obra que ha sido analizada ya más de una vez por su subversión del complejo lenguaje patriarcal cinematográfico del momento. Hoy, Josefina Molina es la Presidenta de Honor de $\mathrm{CIMA}^{2}$ (Asociación de Mujeres Cineastas y de Medios Audiovisuales), que se creó ante la necesidad imperiosa de unirse para reivindicar una mayor participación femenina en los medios audiovisuales. La entrevista que se presenta aquí se realizó antes de que saltara la noticia de la discriminación positiva a mujeres directoras en la nueva Ley del Cine, razón por la que no se menciona en el texto. La asociación que ella preside apoya dicha ley plenamente.

La energía, libertad de opinión y espíritu crítico que Josefina Molina demuestra en este texto parecen haberse mantenido fuertes contra el viento del tiempo.
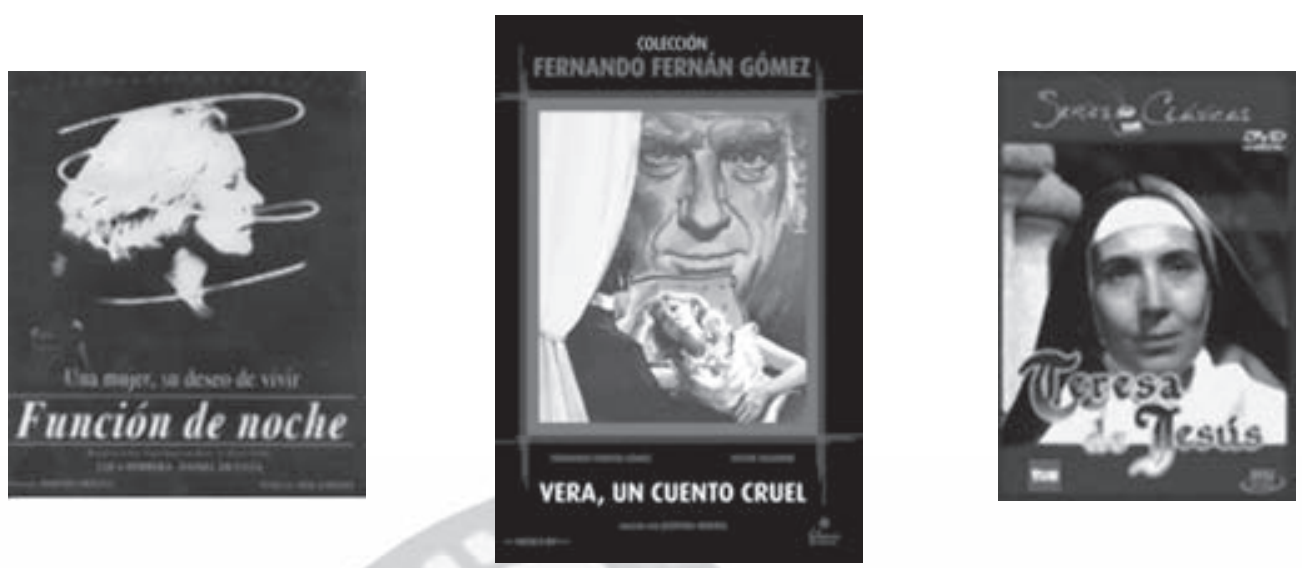

NATALIA CONTRERAS. "Que yo recuerde, nunca en los primeros 20 años de mi vida pude ver una película dirigida por una mujer"3. Esta afirmación suya pone de relieve el ostracismo y las dificultades de las mujeres para obtener visibilidad en el mundo del cine. ¿Cree que en España se ha superado ese tratamiento a las mujeres cineastas? ¿Qué cree que ha cambiado y qué sigue igual?

JOSEFINA MOLINA. Indudablemente ahora se pueden ver películas dirigidas por mujeres y hay una cantidad, que va en aumento, de mujeres cineastas que intentan dar su visión del mundo a través de su obra cinematográfica. Lo que ha cambiado es que después de mucho esfuerzo esto ya no es excepción. Sin embargo, en cuanto a la visibilidad todavía se valoran menos las películas de mujeres, todavía las directoras trabajan con presupuestos menores y sus películas se publicitan menos. Se nos juzga según patrones masculinos y no se escuchan nuestros mensajes con la misma atención. Los hombres creen saberlo todo, incluso sobre nosotras y se sorprenden cuando nos expresamos y nuestro discurso difiere del de ellos; se cierran en banda y deciden en muchos casos descalificar nuestras obras antes que intentar comprenderlas, cosa que llevamos haciendo las mujeres a la inversa durante siglos. Para ver

1 K. VERNON, "Cine de mujeres, contra-cine: la obra fílmica de Josefina Molina", en Discurso femenino actual. Universidad de Puerto Rico, 1995.

2 www.cimamujerescineastas.es/

3 Josefina Molina, "Punto y seguido" en Duoda, n²4, 2003

Quaderns, 5 (2010), pp. 33-36 
el mundo en relieve hacen falta los dos ojos. La Humanidad lleva demasiado tiempo tuerta. Ya es hora de que empecemos a dar nuestro parecer sobre la situación de este planeta, sobre la sociedad que nos rodea, en busca de una manera más amable de vivir. Pero esto llevará tiempo, se hará poco a poco, cuando logremos la igualdad realmente y crezca la solidaridad entre nosotras conscientes de que es nuestro único camino...

NC. El modelo formal de su película Función de noche cuestiona los modelos narrativos tradicionales de la misma manera que, según muchas críticas de género, su obra cuestiona desde el principio las bases del cine narrativo dominante. ¿Considera que esa lucha continúa hoy en día con suficiente ímpetu en nuestro país?

JM. Lo que creo es que las mujeres, tanto en nuestro país, como fuera de él y sobre todo en Europa, están buscando su lenguaje para hacerse entender y para aportar creatividad a las formas cinematográficas. El cine, ya hay que hablar del audiovisual, está cambiando mucho, muchísimo, sobre todo en sus canales de distribución y exhibición. Por tanto, no nos queda otro camino que la búsqueda y la subversión de caminos trillados que ya han dado de sí lo que tenían que dar. Por otra parte creo que la verdadera subversión hoy día consiste en reivindicar el sentido común. Es lo que yo he intentado hacer en cada una de las cosas que he hecho.

NC. Usted ha trabajado mucho en televisión, poniendo de relieve que le daba mayor libertad para experimentar que el cine (consideración que me parece casi visionaria, teniendo en cuenta la corriente de experimentación que se da actualmente en las series de televisión, especialmente proveniente de Estados Unidos). ¿Cree que la incorporación de las mujeres al campo audiovisual (técnicas, guionistas, directoras) ha conllevado una paulatina eliminación de los estereotipos de género para la televisión de mayor audiencia en nuestro país?

JM. Los estereotipos cambian, sí, y son sustituidos por otros. Me preocupan las propuestas de nuevos tipos de mujer que hacen las televisiones de nuestro país. Consisten, muchas veces, en que las mujeres adopten actitudes masculinas, se comporten como si fueran hombres aceptando esas reglas de juego. Yo creo que no es por ahí por donde vamos bien porque esa actitud nos puede conducir a la insolidaridad y al "síndrome de la abeja reina".

NC. ¿Cree que ahora la industria española permite desarrollar la autoría a una cineasta con menos precariedad que antes?

JM. Para mi disgusto, las cineastas actualmente en activo se quejan de la misma precariedad que nos quejábamos las anteriores generaciones. Por eso han creado la Asociación de Mujeres Cineastas y de Medios Audiovisuales CIMA. En esta asociación están Patricia Ferreira, Inés Paris, que preside la junta directiva, Iciar Bollaín, Chus Gutiérrez, Cecilia Bartolomé, Isabel Coixet y hasta doscientas mujeres de los distintos sectores del audiovisual dispuestas a analizar la situación y encontrar caminos hacia la igualdad.

NC. ¿Las nuevas tecnologías digitales y la "democratización" de la creación a través de internet ayudan a ello o fomentan una cinematografía sin cultura previa?

JM. No me atrevo a hacer pronósticos de esta naturaleza. Tengo muchos años y he visto desfilar muchos avances tecnológicos: ninguno, por sí mismo, ha favorecido a las mujeres. Los hombres parecen decir: "nosotros lo inventamos, nosotros lo administramos", y hemos de luchar por acceder a sus ventajas. Ahora bien lo que se puede apreciar sin esfuerzo en los efectos del digital e internet es una ruptura con todas las formas anteriores de relación cread@r-receptor. Todo lo que flexibilice esas formas puede favorecer a las cineastas. Por otra parte, una cinematografía sin cultura previa ya no será cinematografía, será otra cosa. Hay que esperar y ver. 
NC. "Cuando se lucha contra corriente se pierden energías en balde que podían haber sido aplicadas a la propia creación"4. ¿Qué precio cree que ha tenido que pagar desde el punto de vista artístico y creativo por el hecho de haber tenido que abrir un camino nuevo?

JM. He perdido, además de tiempo, profundidad, capacidad de exploración, tanto en los temas como en el lenguaje.

NC. Usted ha afirmado que Carmen, la protagonista femenina de Cinco horas con Mario, representa "el cadáver de una forma de ser mujer que tenía que desaparecer necesariamente" ${ }^{\prime \prime}$. ¿Esa mujer educada en los valores franquistas ha desaparecido de nuestra sociedad, ha adoptado otras formas...?

JM. Tenga usted en cuenta que yo he sido educada en los valores franquistas por las monjas escolapias. Que algunas hayamos hecho un trabajo de demolición interior en busca de la racionalidad y la libertad de pensar, no quiere decir que todas mis contemporáneas hicieran lo mismo. De vez en cuando las veo asomar resistiéndose a desaparecer, tan víctimas, tan equivocadas y tontas creyéndose tan listas como Carmen Sotillos. Me causan una sincera compasión. Por otra parte la intransigencia, la insolidaridad, la ignorancia, la irracionalidad en resumen, adoptan muchas formas y grados hoy en día contra las que es preciso luchar mediante la educación.

NC. Desde el punto de vista de género, ¿hacia dónde cree que se dirige el cine actualmente?

JM. Sinceramente, creo que las mujeres podemos aportar mucho, abrir nuevos caminos. La participación de la mujer en igualdad, cueste el tiempo que cueste, ya es irreversible. Los hombres tendrán que modificar su impulso de dominio porque es lo que nos está llevando - a la Humanidad me refiero- a la catástrofe. A través de los medios audiovisuales las mujeres tenemos una labor inmensa que hacer. Otro mundo, necesitamos otro mundo más justo, más vivible para todos.

NC. ¿Qué consejos les daría a las futuras cineastas de nuestro país?

JM. ¡Qué difícil es dar consejos! Les diría que pase lo que pase no dejen de ser sinceras con ellas mismas, que defiendan su libertad y su creatividad y que no se dejen engañar por lo que dicta el mercado.

\section{Filmografía de Josefina Molina}

- Vera, un cuento cruel (1973) Directora y guionista

- Cuentos eróticos (1979) Directora

- Función de noche (1981) Directora

- Esquilache (1989) Directora y guionista

- Lo más natural (1990) Directora

- Teresa de Jesús (1992) Directora

- La Lola se va a los puertos (1993) Directora

- Series Clásicas: Entre Naranjos (1998) Directora y guionista

4 Op. Cit., 1.

5 J. Molina, Sentada en un rincón. Valladolid, Seminci, 2000. 